\title{
Mehr als 50 Jahre Chansonproduktion auf La Réunion: Maxime Laope (1922-2005)
}

\section{Reiner RUFT (Konstanz), Birgit MERTZ-BAUMGARTNER (Innsbruck)}

Wie vielleicht nicht allgemein bekannt ist, erstreckt sich Frankreich (als einziges Land weltweit) über zwölf Zeitzonen, und das dank seiner Überseegebiete. Der Erstautor dieses Beitrags hat drei davon bereist (St. Pierre-et-Miquelon, Nouvelle Calédonie und La Réunion) und in allen dreien eine eigene Chanson-Tradition vorgefunden. Die letzte Reise führte ihn nach La Réunion....

In Hell-Bourg auf La Réunion, einem reizenden, in einem erloschenen Vulkankrater (Caldera) gelegenen Ort, befindet sich ein wunderschönes, kleines Museum, das Musée Morange - Musée des musiques \& instruments de l'Océan Indien ${ }^{1}$, in dem sich der Besucher auf eine visuelle und auditive Entdeckungsreise der musikalischen Traditionen der Insel begeben kann. Es ist dieses Museum, in dem der Erstautor dieses Beitrags auch das Album Maxime Laope, chapeau l'artiste! (2012) des bekanntesten Auteur-CompositeurInterprète der Insel, Maxime Laope, erworben hat. Auf der Doppel-CD finden sich 44 Chansons Laopes, die er zwischen 1949 und 1989 aufgenommen hatte. Sie bieten einen Einblick in die lange und erfolgreiche Karriere des autodidaktischen Künstlers und spiegeln zugleich ein Stück Mediengeschichte wider, restituieren die CDs doch ausschließlich Chansons, die auf Schellack- ( 78 tours) und Vinylplatten ( 45 tours) aufgenommen worden waren. ${ }^{2}$

Maxime Laope, jamais entendu? Auf La Réunion ist er der grand seigneur der Populärmusik, Vertreter des Séga und des Maloya, einer Musikrichtung, die zur Zeit der Sklaverei auf La Réunion entstand und von der Kolonialverwaltung alsbald aufgrund der kritischen Inhalte verboten wurde (cf. „Séga maloya“, CD 1/19; „Maloya la mode“, CD 2/10, „Maloya tantine“, CD 2/16). Dieses Verbot wurde erst 1982 aufgehoben, als der 20. Dezember 1848 offiziell als Datum der Abschaffung der Sklaverei auf La Réunion anerkannt wurde. 2009 wurde der Maloya zum immateriellen Weltkulturerbe der UNESCO erklärt. Maxime Laope selbst, der als „le grand tonton de la chanson créole“ ${ }^{\text {"3 }}$ gilt, wurde 1997 vom französischen Präsidenten Jacques Chirac zum Ritter der Ehrenlegion ernannt.

Die musikalische Karriere von Maxime Laope begann bereits in den späten 1940er Jahren im Rahmen eines regionalen Songcontests. Diesen konnte er schließlich 1952 gemeinsam mit Bénoîte Boulard mit dem Lied „La rose tombée“ (CD 2/22) für sich entscheiden. Mehr als 30 Jahre sollte die Zusammenarbeit von Laope und Boulard (bis zu deren Tod) dauern. Dank der Unterstützung seines Förderers Georges Fourcade konnte sich Maxime 
Laope aber auch eine Karriere als Solokünstler aufbauen, die ihn zum bekanntesten chanteur créole von La Réunion werden ließ. Diese Karriere reicht bis zu seinem letzten Auftritt 2005, als er 82-jährig im Le Tampon auf La Réunion auf die Bühne gebeten wurde, wo Mitglieder der Association Famille Maxime Laope einige seiner Chansons vortrugen.

Laope gilt als vehementer Verteidiger des Kreolischen, was bereits im ersten Lied der $\mathrm{CD}$ „Mi aim mon patois“ (CD 1/1) deutlich wird. Wenn auch von vielen als ,patois“ und als ,drôle' eingestuft und abgewertet, sei das Kreolische von Réunion doch jene Sprache, die er für seine Kunst bevorzuge („Moin mi préfere mon langage“). Es sei die Sprache, die alle Menschen der Insel verstehen könnten („Puisque dans tout le pays / Tout l'moune i connaît"), und die daher am besten für seine Chansons geeignet sei.

Aber nicht nur die sprachliche Gestaltung der Chansons, d.h. die konsequente Verwendung des Kreolischen, trug ihm den Titel „chanteur populaire“, „chantre de l'âme créole“4 ein, sondern auch die Inhalte seiner Lieder. Er besingt darin Alltägliches, das Leben der Menschen auf La Réunion, ihre Wahrnehmungen der Inselwelt; die Lieder sind Zeugnisse der sozialen Realität einer Epoche, wie seine Tochter Expédite Laope-Cerneaux in einem Interview betont: „[...] c'était la culture populaire. C'était une culture qui n'était pas académique mais qui était le reflet des façons de penser." ${ }^{\text {" }}$

Einige seiner Chansons sind wahre Liebeserklärungen an La Réunion, wie zum Beispiel das schwungvoll-fröhliche „Guette a li“ (CD 2/20), in der er ,seine“ Insel als „mon zoli pays“, als „mon île enchantée“ besingt, deren Schönheit unbeschreiblich sei. Oder das musikalisch getragene Chanson „La Réunion“ (CD 2/3), in dem Laope in Anlehnung an Leconte de Lisle von der Insel als „perle de l'Océan Indien“ singt, deren Schönheit wie jene der Insulanerinnen unbeschreiblich sei. In regelmäßig gebauten Vierzeilern mit Kreuzreim entstehen zu den Klängen des Akkordeons von Loulou Pitou Bilder einer armen („Ici n’a n’a beaucoup / Manioc, chouchou, maïs / De miel, de suc bien doux“"), jedoch wunderschönen Inselwelt.

Manches hat Maxime Laope mit dem Nestor des französischen Chansons, Georges Brassens, gemeinsam. Sie sind fast im gleichen Jahr geboren (Brassens 1921, Laope 1922); ihre Karriere begann etwa in den frühen 1950er Jahren. Manche ihrer Chansons waren zunächst verboten (d.h. durften nicht im staatlichen Radio gespielt werden). Später kam dann aber die große Ehrung: Grand Prix de poésie de L'Académie française für Brassens, Légion d'honneur für Laope. Während Brassens nur etwa 30 Jahre als aktiver Auteur-Compositeur-Interprète vergönnt waren (er starb 1981), dauerte Maxime Laopes aktive Laufbahn von 1949 bis 2002. Was sie unterscheidet, ist ihre Bekanntheit: einerseits Brassens, der berühmte Klassiker des französischen Chansons, andererseits Laope, der trotz seiner reichen Schallplatten- und CD-Produktion (ca. 80) international weitgehend unbekannte Meister der chanson créole. 


\section{Endnoten}

1 http://www.maisonmorange.fr/ (Zugriff 15.11.2018).

2 Die CDs wurden vom Label Takamba produziert, von dem weitere 19 CDs mit Musik aus dem frankophonen Indischen Ozean, z.B. von Mayotte und Mauritius, herausgegeben wurden. Die Initiative für Maxime Laope, Chapeau l'artiste!, ging von der Association Famille Maxime Laope aus. (http://maximelaope.com/lassociation-famille-maxime-laope-fait-connaitre-ses-textes-et-chanson/)

3 „Le grand tonton de la chanson créole“, in: Le Quotidien de La Réunion (16 juillet 2005).

4 https://dpr974.wordpress.com/2015/10/22/maxime-laope-chanteur-populaire-et-chantre-de-lame-creole/ (Zugriff 15.11.2018).

5 https://dpr974.wordpress.com/2015/10/22/maxime-laope-chanteur-populaire-et-chantre-delame-creole/ (Zugriff 15.11.2018). 